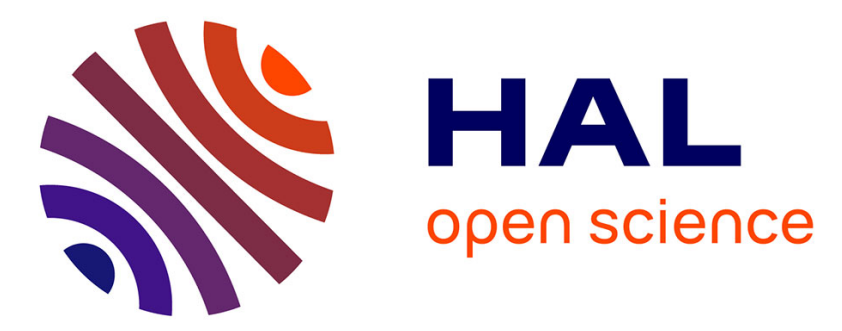

\title{
Proteogenomic insights into uranium tolerance of a Chernobyl's Microbacterium bacterial isolate
}

Nicolas Gallois, Béatrice Alpha-Bazin, Philippe Ortet, mohamed Barakat, Laurie Piette, Justine Long, C. Berthomieu, J. Armengaud, Virginie Chapon

\section{- To cite this version:}

Nicolas Gallois, Béatrice Alpha-Bazin, Philippe Ortet, mohamed Barakat, Laurie Piette, et al.. Proteogenomic insights into uranium tolerance of a Chernobyl's Microbacterium bacterial isolate. Journal of Proteomics, 2018, 177, pp.148-157. 10.1016/j.jprot.2017.11.021 cea-01944196

HAL Id: cea-01944196

https://hal-cea.archives-ouvertes.fr/cea-01944196

Submitted on 5 Dec 2018

HAL is a multi-disciplinary open access archive for the deposit and dissemination of scientific research documents, whether they are published or not. The documents may come from teaching and research institutions in France or abroad, or from public or private research centers.
L'archive ouverte pluridisciplinaire HAL, est destinée au dépôt et à la diffusion de documents scientifiques de niveau recherche, publiés ou non, émanant des établissements d'enseignement et de recherche français ou étrangers, des laboratoires publics ou privés. 


\section{Proteogenomic insights into uranium tolerance of a Chernobyl's}

\section{Microbacterium bacterial isolate}

Gallois Nicolas ${ }^{1}$, Alpha-Bazin Béatrice ${ }^{2}$, Ortet Philippe ${ }^{3}$, Barakat Mohamed ${ }^{3}$, Piette Laurie ${ }^{1}$, Long Justine $^{3}$, Berthomieu Catherine ${ }^{1}$, Armengaud Jean $^{2 \#}$, Chapon Virginie $^{1}$

${ }^{1}$ CEA, CNRS, Aix-Marseille Université, UMR 7265 Biologie Végétale et Microbiologie Environnementales, Laboratoire des Interactions Protéine Métal, 13108 Saint-Paul-lezDurance, France.

${ }^{2}$ Laboratoire Innovations technologiques pour la Détection et le Diagnostic (Li2D), Service de Pharmacologie et Immunoanalyse (SPI), CEA, INRA, F-30207 Bagnols sur Cèze, France.

${ }^{3}$ CEA, CNRS, Aix-Marseille Université, UMR 7265 Biologie Végétale et Microbiologie Environnementales, Laboratoire d'écologie microbienne de la rhizosphère et d'environnements extrêmes, 13108 Saint-Paul-lez-Durance, France

\footnotetext{
\#Corresponding author at:
}

Laboratory «Innovative technologies for Detection and Diagnostics», CEA-Marcoule, DRF-Li2D, PRAE Marcel Boiteux - Départementale 765, BP 17171, F-30200 Bagnols-sur-Cèze cedex, France

Tel: +334667962 77; Fax: +33466796460.

E-mail address: jean.armengaud@cea.fr

URL: http://ibitecs.cea.fr/dsv/ibitecs/Pages/services/spi/li2d.aspx

Keywords

Radionuclides, toxicity, proteogenomics, bioinformatics, toxicoproteomics, Microbacterium 


\section{Abstract}

Microbacterium oleivorans A9 is a uranium-tolerant actinobacteria isolated from the trench T22

located near the Chernobyl nuclear power plant. This site is contaminated with different radionuclides including uranium. To observe the molecular changes at the proteome level occurring in this strain upon uranyl exposure and understand molecular mechanisms explaining its uranium tolerance, we established its draft genome and used this raw information to perform an in-depth proteogenomics study. High-throughput proteomics were performed on cells exposed or not to 10 $\mu \mathrm{M}$ uranyl nitrate sampled at three previously identified phases of uranyl tolerance. We experimentally detected and annotated 1,532 proteins and highlighted a total of 591 proteins for which abundances were significantly differing between conditions. Notably, proteins involved in phosphate and iron metabolisms show high dynamics. A large ratio of proteins more abundant upon uranyl stress, are distant from functionally-annotated known proteins, highlighting the lack of fundamental knowledge regarding numerous key molecular players from soil bacteria.

\section{Biological significance}

Microbacterium oleivorans A9 is an interesting environmental model to understand biological processes engaged in tolerance to radionuclides. Using an innovative proteogenomics approach, we explored its molecular mechanisms involved in uranium tolerance. We sequenced its genome, interpreted high-throughput proteomic data against a six-reading frame ORF database deduced from the draft genome, annotated the identified proteins and compared protein abundances from cells exposed or not to uranyl stress after a cascade search. These data show that a complex cellular response to uranium occurs in Microbacterium oleivorans A9, where one third of the experimental proteome is modified. In particular, the uranyl stress perturbed the phosphate and iron metabolic pathways. Furthermore, several transporters have been identified to be specifically associated to 
uranyl stress, paving the way to the development of biotechnological tools for uranium decontamination.

\section{Introduction}

Radionuclides (RNs) are naturally present in the environment but are redistributed by anthropogenic activities e.g. chemical nitrogen fertilizer use, weapons manufacturing, nuclear research and nuclear fuel production. Several major nuclear accidents such as Chernobyl and Fukushima led to the dispersion of several RNs through the atmosphere in microparticles [1] and in the soil [2]. In Chernobyl, radionuclides-contaminated wastes were buried on site in about 800 trenches. Besides

${ }^{137} \mathrm{Cs}$ and ${ }^{90} \mathrm{Sr}$, other RNs are present in the Chernobyl trench T22, including ${ }^{60} \mathrm{Co},{ }^{154} \mathrm{Eu},{ }^{238,239,}{ }^{240} \mathrm{Pu}$, ${ }^{241} \mathrm{Am}$ and ${ }^{235,238} \mathrm{U}$.

Uranium (U) belongs to the actinide series. It exhibits both radiological and chemical toxicities, and a long half-life, resulting in environmental and human health major concern [3]. As a hard Lewis acid and according to the HSAB theory which qualitatively explains the stability of metal complexes [4], uranyl tends to interact with hard Lewis base such as phosphate, sulfate, carbonate or amine by ionic interactions. It can displace other hard Lewis acids like $\mathrm{Ca}^{2+}$ and $\mathrm{Fe}^{3+}$ in highly oxygenated site. Moreover, different studies have confirmed the affinity between uranium and phosphate or carbonate [5-9], or the replacement of iron by uranyl [10].

Bacteria can interact directly or indirectly with RNs and change their speciation, playing a major role in their mobility and transfer in the environment. The use of both molecular-and culture-based approaches to study bacterial diversity in the trench T22 demonstrated that RNs-contaminated soils host an unexpected diversity of bacteria [11].

During their sampling campaign at Chernobyl, Chapon and colleagues have constructed a large collection of cultured bacteria from the trench $\mathrm{T} 22$ soils offering the opportunity to study the RN 
tolerance of these bacteria [11]. The strain Microbacterium oleivorans A9 (referred as

Microbacterium sp. A9_sp3_-1_2 in [12]) is one of the most uranium-tolerant isolate of this collection. In a previous paper, the interactions between uranium and this bacterium have been investigated and specific exposure conditions in which the bacteria were kept alive while being exposed to soluble forms of uranium have been set-up. With this tightly controlled exposure conditions, it has been shown that Microbacterium oleivorans A9 exhibit three sequential mechanisms involved in uranium detoxification: a rapid metal removal within the first 30 minutes, then an active $\mathrm{U}(\mathrm{VI})$ release in the exposure medium accompanied by a phosphate efflux and a final biomineralization step of uranium in autunite-like mineral phases [12]. For this reason, it constitutes a relevant model to study the mechanisms involved in uranium tolerance and in uranium-bacteria interactions. In bacteria, survival in metal-contaminated environment is mainly achieved through active efflux pumps [13]. If such systems are well-known for a wide variety of non-essential metals, involvement of an efflux system in detoxification of uranium has not yet been described, although up-regulation of genes encoding metal efflux pumps has already been reported for Desulfotomaculum reducens exposed to $\mathrm{U}(\mathrm{VI})$ in anaerobic conditions [14].

The cellular response of Escherichia coli, Acidithiobacillus ferrooxidans and two Anabaena strains upon uranium exposure has already been studied with 2D-PAGE based proteomic methodology [1517]. These studies highlighted an impact of uranium on the bacterial proteome, but the low throughput of this approach allowed identifying only $11,18,45$ and 27 proteins respectively. These may represent only a partial view of the proteins modulated upon uranium stress. Two studies using high-throughput tandem mass spectrometry have deepened the proteome changes occurring in two other bacteria, Geobacter sulfurreducens and Caulobacter crescentus [18, 19]. These papers show that resistance to uranium is a complex cellular response with induction of multiple stress response systems. These four studies, based on gram-negative organisms, have used different uranium concentrations (from 50 to $500 \mu \mathrm{M}$ ) as well as different exposure conditions making any comparison difficult. 
Proteogenomics, the alliance of genomics and proteomics, has proved its efficiency in supporting the existence of genes encoding hypothetical proteins or with unknown function, and even unannotated in the genome for several organisms [20]. This methodology is even more appropriate when a quick focus on mechanisms for which the main players are unknown is required [21-23]. Because, proteogenomics is based on the assignment of MS/MS spectra with a six-frame translation of the genome, time-consuming, resource-dependent and hard-working genome sequence completion steps are bypassed. For example, the annotation of Deinococcus deserti by means of proteogenomics has shown its added value to correct annotation errors in other Deinococcus sp. genomes [21, 24]. The exploration of the halotolerance molecular mechanisms of Tistlia consotensis by proteogenomics based on a draft genome sequence straightforwardly highlighted major changes in response to hypoosmotic and hyper-osmotic conditions [22, 25].

Here, the molecular changes occurring in Microbacterium oleivorans A9 upon uranium exposure were deciphered by means of a proteogenomics approach consisting in draft genome sequencing and high-throughput proteome coverage by next-generation proteomics. Proteomic changes of cells exposed to $10 \mu \mathrm{M}$ uranyl for $30 \mathrm{~min}, 4 \mathrm{~h}$ and $24 \mathrm{~h}$ were investigated. This experimental strategy allowed identification without a priori of soluble and membrane proteins with significantly differing abundances compared to controls, which could be players of the defense mechanism of Microbacterium oleivorans A9 against uranium. Furthermore, these genome and proteome datasets represent invaluable resources to gain insights into the physiology and role of Microbacterium in soils. 


\section{Experimental procedures}

\subsection{Uranium exposure}

The experimental procedure used to expose the bacteria to uranium is described in [12].

Microbacterium oleivorans A9 strain was routinely cultivated in 0.1 X Tryptic Soy Broth (TSB, Difco Laboratories) at $30^{\circ} \mathrm{C}$ with shaking. Cells at exponential growth phase were harvested by centrifugation for $10 \mathrm{~min}$ at $5000 \mathrm{~g}$. From this stage on, samples were maintained at $25^{\circ} \mathrm{C}$ throughout the experiment. The resulting cell pellets were washed twice in $0.1 \mathrm{M} \mathrm{NaCl} \mathrm{pH} 5.0$ and were resuspended at about $6 \times 10^{9}$ cells $\mathrm{mL}^{-1}$ in $0.1 \mathrm{M} \mathrm{NaCl} \mathrm{pH} 5.0$ with 0 (control) or $10 \mu \mathrm{M} \mathrm{U}(\mathrm{VI})$. U(VI) was added as uranyl nitrate $\mathrm{UO}_{2}\left(\mathrm{NO}_{3}\right)_{2} \cdot 6 \mathrm{H}_{2} \mathrm{O}$ (Sigma-Aldrich) from a $7.51 \mathrm{mM}$ stock solution in $16 \mathrm{mM}$ $\mathrm{HNO}_{3}$. No precipitate was observed along the exposure conditions. The nitrate concentration was adjusted to $0.416 \mathrm{mM}$ by adding $\mathrm{NaNO}_{3}$ when needed. Bacteria exposed to $\mathrm{U}(\mathrm{VI})$ and controls were incubated at $25^{\circ} \mathrm{C}$ with shaking. Four independent biological replicates were made for each condition and for each time point. Fractions of $1 \mathrm{ml}$ of cell suspension were taken after $0.5,4$, and $24 \mathrm{~h}$ of uranium exposure. Samples were centrifuged for $5 \mathrm{~min}$ at $8000 \mathrm{~g}$. The resulting supernatants were removed and the pellets were conserved at $-80^{\circ} \mathrm{C}$ until proteomic analysis.

\subsection{Genome of Microbacterium oleivorans A9}

Genomic DNA was sequenced on a HiSeq 2000 sequencing platform (Illumina) by the GenoScreen Company and genome de novo assembling was performed on the reads using ABYSS [26]. The Whole Genome Shotgun project data have been deposited at DDBJ/EMBL/GenBank under the accession number MTIO00000000. For each contig, the ORF translated sequences were extracted from stop codon to stop codon in each of the six possible reading frames. The ORF-derived polypeptide list was restricted to those exhibiting a length of at least 50 amino acids. Proteomic data and proteogenomic procedures were then used to discriminate between false, correct but undetected, and correct and detected protein sequences as described earlier [21, 27]. The ORF sequences for which at least one spectrum has been assigned were kept to create a second database. This step allowed us to identify 
more proteins and to improve qualitatively and quantitatively the MS/MS spectra attribution. The protein sequences were given a cluster of orthologous groups (COG) assignment based on the reference database [28]. Furthermore, enzymes annotation using PRIAM profiles [29] associated to KEGG database [30] allowed the identification of metabolic pathways. An in-house batch program was developed to emphasize metabolic pathways highlighted by proteomic analysis.

\subsection{Proteome sample preparation and trypsin in-gel proteolysis}

Cell pellets (between 2.0 and $4.6 \mathrm{mg}, 3.1 \mathrm{mg}$ average, wet weight) were dissolved in a given volume (100 $\mu \mathrm{L}$ for $1.7 \mathrm{mg}$ of bacterial pellet) of $1 \mathrm{X} \mathrm{NuPAGE}^{\mathrm{TM}}$ LDS Sample Buffer (Invitrogen) supplemented with $2 \% \beta$-mercaptoethanol. Samples were sonicated for $5 \mathrm{~min}$ in a transonic $780 \mathrm{H}$ sonicator and subjected to a 5 min incubation at $99^{\circ} \mathrm{C}$ prior to SDS-PAGE. Samples were subjected to a 3 min short migration in denaturing conditions as previously described [31]. For this, samples were loaded onto a 4-12\% gradient 10-well NuPAGE Bis-Tris (Invitrogen) gel operated with NuPAGE MES (Invitrogen) as running buffer at 200 V. After gel staining with Simply Blue Safe Stain, a ready-to-use Coomassie G250 stain from Invitrogen, the whole proteome content (comprising both soluble and membrane proteins) from each sample was excised as a single piece of gel polyacrylamide band. The 24 resulting polyacrylamide bands were washed with MilliQ water and dehydrated with $\mathrm{CH}_{3} \mathrm{CN}: \mathrm{NH}_{4} \mathrm{HCO}_{3}$ $50 \mathrm{mM}(1: 1 \mathrm{v}: \mathrm{v})$ before addition of $100 \% \mathrm{CH}_{3} \mathrm{CN}$. Gel pieces were then dried for 2 to 5 min under vacuum. For in-gel digestion, dry gel pieces were rehydrated with $100 \mathrm{mM} \mathrm{NH}_{4} \mathrm{HCO}_{3}$ containing 25 $\mathrm{mM}$ DTT and incubated for $10 \mathrm{~min}$ at $56^{\circ} \mathrm{C}$. After removal of the solution, the gel pieces were further treated with $100 \mathrm{mM} \mathrm{NH}_{4} \mathrm{HCO}_{3}$ containing $55 \mathrm{mM}$ iodoacetamide at room temperature and dried under vacuum as before. The gel bands were then processed for in-gel proteolysis with trypsin in presence of $0.01 \%$ ProteaseMax (Promega) as previously described [32].

\subsection{NanoLC-MS/MS analysis}

NanoLC-MS/MS experiments for the 24 resulting peptide mixtures were performed using a QExactive HF mass spectrometer (ThermoFisher) coupled to an UltiMate 3000 LC system (Dionex-LC 
Packings) in similar conditions as those previously described [33]. Peptide mixtures (10 $\mu$ l) were loaded and desalted on-line on a reverse phase precolumn (Acclaim PepMap 100 C18, $5 \mu \mathrm{m}$ bead size, $100 \AA$ pore size, $5 \mathrm{~mm} \times 300 \mu \mathrm{m}$ id) from LC Packings. Peptides were then resolved onto a reverse phase Acclaim PepMap 100 C18 column ( $3 \mu \mathrm{m}, 100 \AA, 500 \mathrm{~mm} \times 75 \mu \mathrm{m}$ id) at a flow rate of $0.3 \mu \mathrm{l} / \mathrm{min}$ with a $180 \mathrm{~min}$ linear gradient of $\mathrm{CH}_{3} \mathrm{CN} / 0.1 \%$ formic acid and injected into the Q-Exactive HF mass spectrometer. The Q-Exactive HF instrument was operated according to a Top20 datadependent acquisition method as previously described [33]. Briefly, a scan cycle was initiated with a full scan of peptide ions in the ultra-high-field Orbitrap analyzer, followed by selection of a single precursor and its dissociation in high energy collisional mode, and MS/MS scans on the 20 most abundant precursor ions. Full scan mass spectra were acquired with an Automatic Gain Control Target set at $3 \times 10^{6}$ ions and a resolution of 60,000 from $\mathrm{m} / \mathrm{z} 350$ to 1,800 . MS/MS scan was initiated at a resolution of 15,000 when the ACG target reached $1 \times 10^{5}$ ions with a threshold intensity of 83,000 and potential charge states of $2+$ and $3+$. Precursor ions were selected with a dynamic exclusion of $10 \mathrm{sec}$ for increasing the reliability of spectral count measurements.

\subsection{Interpretation of mass spectrometry data}

The recorded MS/MS spectra for the 24 samples were merged after being searched against the home-made ORF database. First, peak lists were generated with the MASCOT DAEMON software (version 2.3.2) from Matrix Science using the extract_msn.exe data import filter from the Xcalibur FT package (version 2.0.7) proposed by ThermoFisher. Data import filter options were set as previously described [34] at 400 (minimum mass), 5000 (maximum mass), 0 (grouping tolerance), 0 (intermediate scans), and 1000 (threshold). MS/MS spectra were searched with MASCOT against the ORF database with the following parameters: tryptic peptides with a maximum of 2 miss cleavages during proteolytic digestion, a mass tolerance of $5 \mathrm{ppm}$ on the parent ion and $0.02 \mathrm{Da}$ on the MS/MS, fixed modification for carbamidomethylated Cys (+57.0215) and variable modification for oxidized Met (+15.9949). All peptide matches with a peptide score above its query threshold set at $p \leq 0.05$ with the ORF database and rank 1 were parsed using the IRMa 1.31.1c software [35]. MS/MS spectra 
assigned to several loci were systematically removed. The average error for the determination of peptide mass is $0.59 \mathrm{ppm}$ and the mean MASCOT score is 50.7. A protein was considered validated when at least two different peptides were detected. False-positive identification of proteins was estimated using a reverse decoy database as below $0.1 \%$ with these parameters. The mass spectrometry proteomics data have been deposited in a public repository at the ProteomeXchange Consortium (http://proteomecentral.proteomexchange.org) via the PRIDE partner repository [36] with the dataset identifier PXD005794 and project DOI 10.6019/PXD005794.

The number of MS/MS spectra per protein (spectral counts) was determined for the four replicates of each of the three time points for both conditions. The protein abundances were compared for each time point between the uranyl exposure and the control conditions. For each of these comparisons, the list of non-redundant proteins detected among the six corresponding datasets was established. The total spectral count of each polypeptide was used to rank the proteins from the highest to the lowest detection intensities. The statistical protein variation among the four replicates samples of the two specific exposure conditions compared was calculated using the T-Fold option of the PatternLab 2.0 software [37]. This module allows normalizing the spectral count datasets, calculating the average fold changes with statistics (t-test), and estimating the resulting theoretical false discovery rate. MS/MS data were compiled in Excel (Microsoft) and converted for PatternLab with an Excel home-designed macro. Normalization was done taking into account the total number of spectral count for each sample, taking at least two readings per protein. A minimum value of 1 was added systematically to all spectral count values in order to consider missing values as a standard PatternLab normalization. Parameters for the comparisons were as follows: minimum fold change of 1.5, minimum p-value of 0.05 and BH-FDR Alfa of 0.15 . Normalized spectral abundance factor (NSAF) for each protein was calculated using the formula: (spectral counts / theoretical molecular weight) $x$ 1000, see [34]. 


\section{Results and discussion}

\subsection{Microbacterium oleivorans A9 genome annotation}

The main characteristics of Microbacterium oleivorans A9 genome is described in [38]. Briefly, the genome size is around $2.95 \mathrm{Mbp}$. The $\mathrm{G}+\mathrm{C}$ content of the genome is $68.33 \%$. COG assignment for the resulting polypeptide dataset shows that two classes are predominant: proteins involved in metabolism of amino acids (74 proteins) on the first hand, and those involved in metabolism of carbohydrates (66 proteins) on the other. A search against the BacMet database [39], which comprises antibacterial biocides and metal resistance genes, highlights the presence of 104 unique metal resistance genes such as actP gene which encodes a copper-transporting P-type ATPase, ars $B$ gene which encodes an arsenic pump membrane protein or yief gene which encodes a chromate reductase. We found a 16S rRNA gene copy in the genome, exhibiting $99 \%$ sequence identity with Microbacterium oleivorans $16 \mathrm{~S}$ rRNA gene. Moreover, the assembling results are strikingly similar to those obtained for Microbacterium oleivorans strain RIT293 (RefSeq NZ_JFYO00000000.1) [40] with a median total length of $2.9 \mathrm{Mbp}$, a $\mathrm{G}+\mathrm{C}$ content of $69 \%$ and a total of 2,732 protein-coding genes. This genome version comprises 11 contigs with a N50 parameter at 467,109 bp.

\subsection{Shotgun proteogenomics of Microbacterium oleivorans A9}

\section{Proteogenomics quick panorama}

Figure 1 shows the strategy applied here for quickly deciphering the proteome dynamics from resting cells exposed or not to $10 \mu \mathrm{M}$ uranium. A total of 1,221,282 MS/MS spectra were recorded. Most of these spectra were of high quality as revealed by the high percentage of assignment obtained (61.1\%) at $p$-value 0.05 . For interpreting MS/MS spectra, a six reading frame translated ORF database was created. This proteogenomics database comprised a total of 30,853 putative polypeptide sequences, totaling 4,903,573 amino acids with an average of 159 amino acids per putative polypeptide and 2,064 as longest length. A total of 746,092 MS/MS spectra could be assigned in first intention, allowing certifying the presence of 1,504 proteins detected with at least two different 
peptides (Supplementary data Table S1). Because of the unusual large size of the six reading frame

244 ORF database(30,853 putative polypeptide sequences instead of 2813 annotated coding DNA sequences), a second round of search was initiated after reducing the database to the proteins detected in the first round as proposed previously for improving the sensitivity of proteogenomics studies [41]. The second search led to the assignation of 747,621 peptide-to-spectrum matches, certifying the detection of 17,027 unique peptide sequences and 1,532 non-redundant proteins identified with at least two different peptides (Supplementary data Table S2). This two-round search allows increasing the number of proteins validated with at least two different peptides (1532 instead of 1504) and enhances the number of assigned MS/MS spectra (747 621 instead of 746092 ). This dataset compares favorably with previous studies of bacteria exposed to uranium, as a dataset of less than 950 proteins were reported from Caulobacter crescentus [19] and 1,363 proteins were listed from Geobacter sulfurreducens [18]. The proteomic dataset obtained here represents 54\% (including $15 \%$ of membrane proteins) of the predicted protein-coding genes found in the draft genome of Microbacterium oleivorans A9 [38]. The distribution of the peptides detected during our experiment along the chimeric genome of Microbacterium oleivorans A9 is uniform and confirm the validity of this proteogenomics approach, as previously discussed for the proteogenomics mapping of the alphaproteobacterium Tistlia consotensis [22].

\section{Functional categorization of the detected proteins and relative abundances}

The dataset of 1,532 identified proteins were classified into 22 COG categories. Table 1 shows the functional classification of the mass-spectrometry certified global proteome. Most of the detected proteins (50\%) are distributed in five classes: hypothetical proteins (15\%), amino acid metabolism (11\%), carbohydrate metabolism (9\%), translation, ribosomal structure, and biogenesis $(9 \%)$ and transcription (6\%). The remaining 17 classes represent less than $5 \%$ each (Table 1 ). The prevalence of the same classes has been shown in previous studies $[18,19]$, but here, the large number of uncharacterized proteins is indicative of an important lack of knowledge regarding soil gram-positive bacteria. 36 proteins account for $25 \%$ of the total proteome detected, and thus are the key molecular 
draft horses within the cells. These 36 most abundant proteins detected throughout the study as evaluated with their normalized spectral abundance factor (NSAF) are given in Supplementary data Table S2. The most abundant protein is the HU bacterial nucleoid DNA-binding protein involved in DNA structuration. Two of the top five most abundant proteins are the chaperonin GroEL (1.28\%) and the co-chaperonin GroES (1.06\%). These two proteins form the binary GroEL/GroES complex, which mediates proper folding of many proteins. The sub-unit GroEL is specifically known for its important role both in normal and stressful conditions as well as in the resistance towards toxic metals [42]. As expected the ribosomal proteins are abundant since the cells were collected during the exponential growth phase. The 100 most abundant proteins represent $46.1 \%$ of total NSAF. Amongst these, 16 proteins ( $8.3 \%$ of total NSAF) are components of the small ribosomal subunit and 27 proteins (10.6\% total NSAF) belong to the large ribosomal subunit. This abundance of ribosomal proteins has already been observed [23,34]. Within the most abundant proteins, several are involved in energy metabolism such as the F0F1-type ATP synthase $(0.78 \%$ and $0.57 \%$ respectively).

\subsection{Proteome dynamics upon uranium stress}

\section{Common differentially produced proteins over the time course of the experiment}

Proteins with significant abundance changes (fold change $\geq 1.5$ and $p$-value $\leq 0.05$ ) in uraniumexposed condition versus control were listed at each time point. A total of 592 proteins met the criteria: 391 at $0.5 \mathrm{~h}, 294$ at $4 \mathrm{~h}$ and 122 at $24 \mathrm{~h}$. The decrease of differentially produced proteins over time is due to the non-growing exposure conditions. Figure $\mathbf{2}$ shows a Venn diagram representation where the numbers of these proteins are reported for each condition, highlighting the proteins specific of a given time point and those common in two or three time points. A relatively small set of 24 proteins were shared along the whole kinetic. Remarkably seven of these 24 proteins are predicted to be ABC-type transporters. Their spectrum activities appeared to be broad as they share significant sequence similarities with dipeptide/oligopeptide/nickel, $\mathrm{Fe}^{3+}$-hydroxamate, multidrug or enterocholin transporters. A serine protease and a DNA-binding transcriptional regulator belonging 
to the PadR family are also found more abundant in presence of uranium for the three time points: 1.7, 1.6 and 4.6-fold; 2.1-fold, 2.6-fold and 2.0-fold, respectively. Members of the PadR family regulate different pathways such as multidrug resistance and detoxification [43]. A total of 128 proteins were found significantly more abundant in $0.5 \mathrm{~h}$ and $4 \mathrm{~h}$ samples of exposure to uranium compared to controls. These 128 proteins covered a large variety of molecular functions making difficult to draw specific uranium responsive pathways. Six ABC-type transporters were observed among this large panel of up-regulated proteins. They are predicted to be involved in amino acid, sugar, cobalamin, $\mathrm{Fe}^{3+}$ siderophore and glycerol-3-phosphate transport. These data reinforce the hypothesis that bacteria deploy a rather large panel of transport machineries to respond to uranium exposure. Four proteins involved in cell division are also significantly more abundant at these two initial phases of uranium exposure: the cell division proteins FtsI and FtsQ, and two chromosome partitioning ATPases. Such observation reinforces the idea that cells are viable and active.

Once again, a link with iron metabolism is highlighted in the proteins common after $0.5 \mathrm{~h}$ and $24 \mathrm{~h}$ of uranium exposure with the presence of $\mathrm{ABC}$-type $\mathrm{Fe}^{3+} /$ spermidine/putrescine transport system (2.0 and 1.8-fold), the ferredoxin-NADP reductase (1.9 and 1.9-fold), the deferrochelatase/peroxidase EfeB (1.7 and 1.8-fold) and the NADPH-dependent ferric siderophore reductase (1.8 and 1.6-fold). Interestingly, a protein predicted to be a DNA-binding transcriptional regulator belonging to the ArsR family is found significantly more abundant at $0.5 \mathrm{~h}$ but less abundant after $24 \mathrm{~h}$ uranium exposure. This regulator is known to repress expression of stress-induced operons involved in toxic metal ion tolerance [44]. This suggests that Microbacterium oleivorans A9 first represses these genes when cells are at the initial stage of uranium contact, but need the expression of these genes when the uranium is intracellularly biomineralized and so less bioavailable.

A comparison of the significant changes of protein abundances between $4 \mathrm{~h}$ and $24 \mathrm{~h}$ of exposure shows that 17 proteins are in common for these two time points. Three are related to osmoregulation (DNA-binding response regulator of the OmpR family and of the AcrR family, 
maltooligosyltrehalose synthase) which is consistent with the exposure condition used i.e. $\mathrm{NaCl}$

$0.1 \mathrm{M}$.

\section{Proteins specifically modulated at a given time point}

A large set of proteins (391) has been found significantly modulated in terms of abundance after $0.5 \mathrm{~h}$ exposure to $\mathrm{U}(\mathrm{VI})$ as compared to the control. Table $\mathbf{2}$ shows the proteins with the most important changes (fold-change $\geq 3.5$ ). The chorismate mutase exhibited the highest fold-change (5.8-fold), while its homologue from Geobacter sulfureducens has been previously shown to decrease in response to uranium [18]. This protein is involved in phenylalanine and tyrosine synthetic pathway through the conversion of chorismate in prephenate. As reported in Figure 3, five other proteins from the same pathway have an increased abundance upon uranium exposure, including the isochorismate synthase (2.6-fold) and the aminotransferase/4-amino-4-deoxychorismate lyase (2.0fold). A protein involved in ABC-type glycerol-3-phosphate transport, two proteins responsible of acyl transfer to glycerol-3-phosphate and the CDP-glycerol glycerophosphotransferase were more abundant in uranium condition. Glycerol-3-phosphate appears as an important metabolite which may provide phosphate for complexing and immobilizing uranium [45]. Major changes affected the phosphate metabolism as evidenced by the important number (59) of proteins related to this metabolism. A large panel of phosphatases (16 polypeptides) is found in higher amounts after uranium stress. These enzymes are involved in phosphate removal mainly from sugar (fructose, trehalose) and from amino acids (serine, threonine).

Regarding the two other time points analyzed by high-throughput proteomics, the most modulated protein detected after $4 \mathrm{~h}$ is also the protein with the higher abundance after $24 \mathrm{~h}$ of uranium exposure compared to control (11-fold and 25 -fold respectively). This protein shares some sequence similarities (63\% identity) to the uncharacterized Ykol membrane protein of Microbacterium oleivorans LKL04 (Table 2). It presents a PepSY domain (pfam 03413) hypothetically involved in inhibition of a peptidase activity. Based on the TMHMM predictive tool [46], one transmembrane segment has been identified in the Microbacterium oleivorans A9 protein homolog from residues 39 
to 61 , suggesting that the longest part of this protein is extracellular (residues 62 to 247). Regarding the synteny in Microbacterium oleivorans A9 genome, a signal transduction histidine kinase is adjacent to this protein, indicating a possible involvement in signaling function. One of the four proteins for which the abundance decreased at $4 \mathrm{~h}$ of uranium exposure is the glutaredoxin which can interact physically with a mercury/uranyl reductase (MerA) and plays a role in toxic metals resistance [47]. After 24h exposure, 12 transporters involved in the transport of diverse compounds (lipoprotein, $\mathrm{Fe}^{3+}$-hydroxamate, dipeptide/oligopeptide/nickel, enterochelin, $\mathrm{Fe}^{3+} /$ spermidine/putrescine) are more abundant in the uranium condition compared to the control (Table 2). A DNA-binding response regulator of the NarL/FixJ family is also more detected (5.3-fold). The homologous regulator from Escherichia coli has been characterized and found to control nitrateand nitrite-regulated gene expression. This is concordant with the lower detection (-2.1-fold) of a ferredoxin subunit of the nitrite reductase. In the present exposure condition, nitrate has been added in both control and uranium conditions and probably contributes to modify the production of these two proteins.

\section{Phosphate metabolism}

In our previous study, we have evidenced a phosphate efflux concomitant to the uranium efflux between $0.5 \mathrm{~h}$ and $4 \mathrm{~h}$ exposure and the intracellular formation of autunite, a mineral made of $U, P$ and $\mathrm{Ca}$, suggesting a strong connection between phosphate and uranium [12]. Among these proteins, the phosphohistidine phosphatase SixA is the most up-produced protein ( 3.5 fold-change at $0.5 \mathrm{~h}$ and $4 \mathrm{~h}$ ). Its precise role is still unclear but its involvement in a signal transduction circuitry through down-regulation of the ArcB-to-ArcA phosphorelay has been shown under anaerobic conditions in Escherichia coli [56]. On the other hand, the increase abundance of the broad specificity phosphatase PhoE only after 4h (2.3 fold-change) is congruent with the phosphate efflux observed in our previous experiment [12]. Several components of an ABC-type glycerol-3-phosphate transport system have also a significant positive fold-change. No such component is found more abundant after $24 \mathrm{~h}$ exposure probably because the phosphate is complexed with uranium leading to autunite 
accumulation. The glycerol-3-phosphate has been demonstrated as a source of phosphate for the precipitation of uranium [45]. A polyphosphate kinase shows an up-production after $0.5 \mathrm{~h}$ (foldchange of 1.8). It can act as a defense mechanism by constituting a phosphate reserve that will be used latter to form uranyl-phosphate complex. As reported in Figure 4, the genomic context of this kinase reveals a locus with seven adjacent genes, possibly organized as an operon. These genes are all related to phosphate metabolism. The operon comprises a transcriptional regulatory protein, the phosphohistidine phosphatase SixA and four components of an ABC-type phosphate transport system. Five of this six genes encode proteins which have been found more abundant in uranium condition but with low statistical confidence ( $p$-value above 0.05 ) or with significant but low foldchange. Noteworthy, this cluster of genes is conserved amongst several Microbacterium species from our collection (data not shown). In this work, several proteins involved in phosphate metabolism were modulated upon uranium exposure. The relationships between uranium and phosphate metabolism have also been evidenced by others [57-59].

Reminding that uranium can bind to highly oxygenated sites such as phosphate and carbonate, it is interesting to point out that a component of an $\mathrm{ABC}$-type nitrate/sulfonate/bicarbonate transport system shows a significant increase in terms of abundance ( 1.9 fold-change) after an exposure of $4 \mathrm{~h}$, in the same time as uranium and phosphate efflux occur. Several cations transporters $\left(\mathrm{K}^{+}, \mathrm{Mn}^{2+}, \mathrm{Zn}^{2+}\right.$, $\left.\mathrm{Mg}^{2+}, \mathrm{Co}^{2+}\right)$ are also induced upon uranium exposure. One can speculate that one of these transporters may be involved in uranyl efflux.

\section{Iron metabolism}

In our previous study and unlike to phosphate metabolism, we obtained no element suggesting an effect of uranium on iron metabolism [12]. Here, however, a strong impact on iron metabolism is highlighted through the large number of proteins related to iron metabolism more abundant under uranyl stress (19 out of 43 proteins classified in the "Inorganic ion metabolism and transport" category). Most of them are components of the siderophore iron uptake system, either ABCtransport type subunits or siderophore modification enzymes. Among these 19 proteins, two ABC- 
type $\mathrm{Fe}^{3+}$-hydroxamate transport systems and one $\mathrm{ABC}$-type enterocholin transport system are found systematically more abundant at the three time points (fold changes of 1.7, 2.1 and 2.8 respectively). Hydroxamate and enterocholin are siderophores, low molecular compounds produced by bacteria to scavenge iron (Fe(III)) in iron starvation conditions. The involvement of siderophores in tolerance to toxic metals has already been demonstrated [48]. The ATPase component of an ABC-type cobalamin/Fe $\mathrm{Fe}^{3+}$-siderophore transport system is also found in higher proportion at $0.5 \mathrm{~h}$ and $4 \mathrm{~h}$ with fold changes of 1.6 and 1.7 respectively. Moreover, the abundance of a NADPH-dependent ferric siderophore reductase increased upon uranium exposure: fold change of a 1.8 and 1.6 at $0.5 \mathrm{~h}$ and $24 \mathrm{~h}$, respectively. This protein is involved in the release of iron from siderophore. Involvement of siderophores in the resistance to uranium has been poorly studied, but hydroxamate has been shown to bind uranium and to be able to chelate more efficiently uranium with the carbonate form [49]. In addition, induction of siderophore production in response to uranium stress has been shown for the marine cyanobacterium Synechococcus elongatus BDU 130911 [50]. Taken together, these data suggest that uranium could interact with siderophore in Microbacterium oleivorans A9. One attractive hypothesis is that uranium could then enter the cells via this pathway.

Two components (EfeO and $\mathrm{EfeB}$ ) of the EfeUOB transporter were also detected in higher amounts in our dataset. This transporter is involved in iron uptake in Bacillus subtilis [51]. EfeB is a peroxidase involved in oxidation of ferrous iron to ferric iron which allows its binding by the EfeO component. This protein shows a regular increase at $0.5 \mathrm{~h}, 4 \mathrm{~h}$, and $24 \mathrm{~h}$ with fold changes of $1.7,1.8$ and 1.8 , respectively. Moreover, EfeB presents the ability to reduce the reactive oxygen species formed in presence of ferrous iron and thus, confers protection to the cell. The prediction of both a cupredoxinlike domain and an imelysin peptidase with a highly conserved HXXE motif confirm that we are dealing with the EfeO component and not the EfeM for which the cupredoxin-like domain is absent [52]. The EfeO component is a ferric iron binding protein and is able to transfer its substrate to the permease EfeU. The variation in the abundance of EfeO during the experiment is not significant. The EfeU component remained undetected despite its prediction in the genome. The EfeUOB transporter 
of Escherichia coli has been shown to be induced under low pH condition [53]. This three-component transporter is also found in Bacillus subtilis and was shown to be involved in high-affinity uptake of both ferrous (Fe(II)) and ferric iron (Fe(III)) [51]. Taken together, these results suggest that uranium exposure is perceived by Microbacterium oleivorans A9 as an iron starvation, thus enhancing the synthesis of iron uptake systems. This result is in line with what has been shown for Geobacter sulfurreducens in which uranium induces the Fur operon [18]. Other biological molecules involved in iron metabolism, e.g. transferrin, have been shown to be able to link uranium and can constitute a way for uranium to be transported in the cells [55].

\section{Concluding remarks}

The high-throughput proteogenomic methodology applied to Microbacterium oleivorans A9 allows to quickly identify a large number of proteins and highlights those that could be involved in uranium tolerance. The proteome coverage obtained here is higher than previous proteomic studies devoted at exploring the proteome under uranium stress $[18,19]$. Microbacterium oleivorans A9 modifies drastically its proteome upon uranium exposure. As previously hypothesized, proteins involved in phosphate metabolism are found in larger abundances under uranium stress due to higher synthesis or poorer degradation or both of these mechanisms. More surprisingly, proteins related to iron metabolism were detected with significant changes in abundance. The detailed relationships between uranium response and iron metabolism are unknown at the moment. However, based on our current results it can be hypothesized that uranium may enter the cells via siderophore transportation. This will be further investigated. The detection of $15 \%$ of functionally unassigned proteins highlights the lack of knowledge regarding proteins with potentially key roles in response to uranium stress. Focusing on the most interesting protein candidates could be done by a comparative analysis using high-throughput proteogenomics between Microbacterium oleivorans A9 and other Microbacterium isolates differing in uranium sensitivity such as Microbacterium lemovicicum ViU22 [60] which is uranium-sensitive. 
450

\section{Acknowledgments}

Nicolas Gallois was financially supported by the Commissariat à l'Energie Atomique et aux Energies

Alternatives (CEA) by means of the program "Thèse Amont-Aval" directed by Yves Bréchet, Haut-

Commissaire à l'Energie Atomique. The project was supported by CEA through the Toxicology

program (BEnUr). We thank Microb\&co for all the writing advices given during the $7^{\text {th }} I C M E$.

\section{References}

[1] Y. Abe, Y. lizawa, Y. Terada, K. Adachi, Y. Igarashi, I. Nakai, Detection of uranium and chemical state analysis of individual radioactive microparticles emitted from the Fukushima nuclear accident using multiple synchrotron radiation X-ray analyses, Anal Chem 86(17) (2014) 8521-8525.

[2] D. Bugai, V. Kashparov, L. Dewiére, Y. Khomutinin, S. Levchuk, V. Yoschenko, Characterization of subsurface geometry and radioactivity distribution in the trench containing Chernobyl clean-up wastes, Environ Geol 47(6) (2005) 869-881.

[3] C.R. Cothern, W.L. Lappenbusch, J.A. Cotruvo, Health effects guidance for uranium in drinking water, Health physics 44 Suppl 1 (1983) 377-84.

[4] R.G. Pearson, Hard and Soft Acids and Bases, J Am Chem Soc 85(22) (1963) 3533-\&.

[5] R.J. Reeder, M. Nugent, C.D. Tait, D.E. Morris, S.M. Heald, K.M. Beck, W.P. Hess, A. Lanzirotti, Coprecipitation of uranium(VI) with calcite: XAFS, micro-XAS, and luminescence characterization, Geochim Cosmochim Acta 65(20) (2001) 3491-3503.

[6] N. Renninger, R. Knopp, H. Nitsche, D.S. Clark, J.D. Keasling, Uranyl precipitation by Pseudomonas aeruginosa via controlled polyphosphate metabolism, Appl Environ Microbiol 70(12) (2004) 7404-12. [7] P. Yong, L.E. Macaskie, Role of citrate as a complexing ligand which permits enzymically-mediated uranyl ion bioaccumulation, Bull Environ Contam Toxicol 54(6) (1995) 892-9.

[8] M.L. Merroun, S. Selenska-Pobell, Bacterial interactions with uranium: an environmental perspective, J Contam Hydrol 102(3-4) (2008) 285-295.

[9] A. Nakajima, T. Horikoshi, T. Sakaguchi, Studies on the Accumulation of Heavy-Metal Elements in Biological-Systems .5. Ion Effects on the Uptake of Uranium by Chlorella-Regularis, Agr Biol Chem Tokyo 43(3) (1979) 625-629.

[10] M. Bouby, I. Billard, M. J., I. Rossini, Complexation of uranium VI with the siderophore pyoverdine, Radiochim Acta 80 (1998) 95-100.

[11] V. Chapon, L. Piette, M.-H. Vesvres, F. Coppin, C.L. Marrec, R. Christen, N. Theodorakopoulos, L. Février, S. Levchuk, A. Martin-Garin, C. Berthomieu, C. Sergeant, Microbial diversity in contaminated soils along the T22 trench of the Chernobyl experimental platform, Appl Geochem 27(7) (2012) 13751383.

[12] N. Theodorakopoulos, V. Chapon, F. Coppin, M. Floriani, T. Vercouter, C. Sergeant, V. Camilleri, C. Berthomieu, L. Fevrier, Use of combined microscopic and spectroscopic techniques to reveal 
interactions between uranium and Microbacterium sp. A9, a strain isolated from the Chernobyl exclusion zone, J Hazard Mater 285 (2015) 285-293.

[13] D.H. Nies, Microbial heavy-metal resistance, Appl Microbiol Biotechnol 51(6) (1999) 730-50. [14] P. Junier, E.D. Vecchia, R. Bernier-Latmani, The Response of Desulfotomaculum reducens MI-1 to U(VI) Exposure: A Transcriptomic Study, Geomicrobiol J 28(5-6) (2011) 483-496.

[15] A. Khemiri, M. Carriere, N. Bremond, M.A. Ben Mlouka, L. Coquet, I. Llorens, V. Chapon, T. Jouenne, P. Cosette, C. Berthomieu, Escherichia coli response to uranyl exposure at low pH and associated protein regulations, PloS one 9(2) (2014) e89863.

[16] L. Dekker, F. Arsene-Ploetze, J.M. Santini, Comparative proteomics of Acidithiobacillus ferrooxidans grown in the presence and absence of uranium, Res Microbiol 167(3) (2016) 234-239. [17] B. Panda, B. Basu, C. Acharya, H. Rajaram, S.K. Apte, Proteomic analysis reveals contrasting stress response to uranium in two nitrogen-fixing Anabaena strains, differentially tolerant to uranium, Aquatic toxicology 182 (2017) 205-213.

[18] R. Orellana, K.K. Hixson, S. Murphy, T. Mester, M.L. Sharma, M.S. Lipton, D.R. Lovley, Proteome of Geobacter sulfurreducens in the presence of U(VI), Microbiology 160(Pt 12) (2014) 2607-2617. [19] M.C. Yung, J. Ma, M.R. Salemi, B.S. Phinney, G.R. Bowman, Y. Jiao, Shotgun proteomic analysis unveils survival and detoxification strategies by Caulobacter crescentus during exposure to uranium, chromium, and cadmium, J Proteome Res 13(4) (2014) 1833-1847.

[20] J. Armengaud, Next-generation proteomics faces new challenges in environmental biotechnology, Curr Opin Biotechnol 38 (2016) 174-182.

[21] A. de Groot, R. Dulermo, P. Ortet, L. Blanchard, P. Guerin, B. Fernandez, B. Vacherie, C. Dossat, E. Jolivet, P. Siguier, M. Chandler, M. Barakat, A. Dedieu, V. Barbe, T. Heulin, S. Sommer, W. Achouak, J. Armengaud, Alliance of proteomics and genomics to unravel the specificities of Sahara bacterium Deinococcus deserti, PLoS genetics 5(3) (2009) e1000434.

[22] C. Rubiano-Labrador, C. Bland, G. Miotello, P. Guerin, O. Pible, S. Baena, J. Armengaud, Proteogenomic insights into salt tolerance by a halotolerant alpha-proteobacterium isolated from an Andean saline spring, J Proteomics 97 (2014) 36-47.

[23] X. Zhu, S. Xie, J. Armengaud, W. Xie, Z. Guo, S. Kang, Q. Wu, S. Wang, J. Xia, R. He, Y. Zhang, Tissue-specific proteogenomic analysis of Plutella xylostella larval midgut using a multialgorithm pipeline, Molecular \& cellular proteomics 15(6) (2016) 1791-807.

[24] M. Baudet, P. Ortet, J.C. Gaillard, B. Fernandez, P. Guerin, C. Enjalbal, G. Subra, A. de Groot, M. Barakat, A. Dedieu, J. Armengaud, Proteomics-based Refinement of Deinococcus deserti Genome Annotation Reveals an Unwonted Use of Non-canonical Translation Initiation Codons, Molecular \& Cellular Proteomics 9(2) (2010) 415-426.

[25] C. Rubiano-Labrador, C. Bland, G. Miotello, J. Armengaud, S. Baena, Salt Stress Induced Changes in the Exoproteome of the Halotolerant Bacterium Tistlia consotensis Deciphered by Proteogenomics, PloS one 10(8) (2015) e0135065.

[26] J.T. Simpson, K. Wong, S.D. Jackman, J.E. Schein, S.J. Jones, I. Birol, ABySS: a parallel assembler for short read sequence data, Genome Res 19(6) (2009) 1117-23.

[27] J. Armengaud, C. Bland, J. Christie-Oleza, G. Miotello, Microbial proteogenomics, gaining ground with the avalanche of genome sequences, J Bacteriol Parasitol S3-001 (2011).

[28] R.L. Tatusov, M.Y. Galperin, D.A. Natale, E.V. Koonin, The COG database: a tool for genome-scale analysis of protein functions and evolution, Nucleic Acids Res 28(1) (2000) 33-6.

[29] C. Claudel-Renard, C. Chevalet, T. Faraut, D. Kahn, Enzyme-specific profiles for genome annotation: PRIAM, Nucleic Acids Res 31(22) (2003) 6633-9.

[30] M. Kanehisa, Y. Sato, M. Kawashima, M. Furumichi, M. Tanabe, KEGG as a reference resource for gene and protein annotation, Nucleic Acids Res 44(D1) (2016) D457-62.

[31] E.M. Hartmann, F. Allain, J.C. Gaillard, O. Pible, J. Armengaud, Taking the shortcut for highthroughput shotgun proteomic analysis of bacteria, Methods Mol Biol 1197 (2014) 275-285.

[32] G. Clair, S. Roussi, J. Armengaud, C. Duport, Expanding the known repertoire of virulence factors produced by Bacillus cereus through early secretome profiling in three redox conditions, Molecular \& cellular proteomics 9(7) (2010) 1486-98. 

J.C. Gaillard, G. Lagniel, J. Armengaud, M. Carriere, S. Chedin, Y. Boulard, S. Pin, J.P. Renault, J.C. Aude, J. Labarre, RNA-binding proteins are a major target of silica nanoparticles in cell extracts, Nanotoxicology 10(10) (2016) 1555-1564. [34] J.A. Christie-Oleza, B. Fernandez, B. Nogales, R. Bosch, J. Armengaud, Proteomic insights into the lifestyle of an environmentally relevant marine bacterium, ISME J 6(1) (2012) 124-35.

[35] V. Dupierris, C. Masselon, M. Court, S. Kieffer-Jaquinod, C. Bruley, A toolbox for validation of mass spectrometry peptides identification and generation of database: IRMa, Bioinformatics 25(15) (2009) 1980-1. . Wright, H.W. van den Toorn, B. van Breukelen, A.J. Heck, N. Hulstaert, L. Martens, F. Reisinger, A. Csordas, D. Ovelleiro, Y. Perez-Rivevol, H. Barsnes, H. Hermjakob, J.A. Vizcaino, The PRoteomics IDEntification (PRIDE) Converter 2 framework: an improved suite of tools to facilitate data submission to the PRIDE database and the ProteomeXchange consortium, Molecular \& cellular proteomics 11(12) (2012) 1682-9. [37] P.C. Carvalho, J. Hewel, V.C. Barbosa, J.R. Yates lii, Identifying differences in protein expression levels by spectral counting and feature selection, Genet Mol Res 7(2) (2008) 342-356. [38] P. Ortet, N. Gallois, J. Long, M. Barakat, V. Chapon, Draft genome sequence of Microbacterium oleivorans strain A9, a bacterium isolated from Chernobyl radionuclide-contaminated soil, Genome announcement 999(5) (2017) e00092-17.

[39] C. Pal, J. Bengtsson-Palme, C. Rensing, E. Kristiansson, D.G. Larsson, BacMet: antibacterial biocide and metal resistance genes database, Nucleic Acids Res 42(Database issue) (2014) 737-743. [40] H.Y. Gan, H.M. Gan, M.A. Savka, A.J. Triassi, M.S. Wheatley, L.B. Smart, E.S. Fabio, A.O. Hudson, Whole-genome sequences of 13 endophytic bacteria isolated from shrub willow (salix) grown in geneva, new york, Genome announcement 2(3) (2014) e00288-14.

[41] P. Jagtap, J. Goslinga, J.A. Kooren, T. McGowan, M.S. Wroblewski, S.L. Seymour, T.J. Griffin, A two-step database search method improves sensitivity in peptide sequence matches for metaproteomics and proteogenomics studies, Proteomics 13(8) (2013) 1352-7.

[42] J.S. Weissman, H.S. Rye, W.A. Fenton, J.M. Beechem, A.L. Horwich, Characterization of the active intermediate of a GroEL-GroES-mediated protein folding reaction, Cell 84(3) (1996) 481-90.

[43] G. Fibriansah, A.T. Kovacs, T.J. Pool, M. Boonstra, O.P. Kuipers, A.M. Thunnissen, Crystal structures of two transcriptional regulators from Bacillus cereus define the conserved structural features of a PadR subfamily, PloS one 7(11) (2012) e48015.

[44] S. Silver, T. Phung le, A bacterial view of the periodic table: genes and proteins for toxic inorganic ions, J Ind Microbiol Biotechnol 32(11-12) (2005) 587-605.

[45] R.J. Martinez, M.J. Beazley, M. Taillefert, A.K. Arakaki, J. Skolnick, P.A. Sobecky, Aerobic uranium (VI) bioprecipitation by metal-resistant bacteria isolated from radionuclide- and metal-contaminated subsurface soils, Environ Microbiol 9(12) (2007) 3122-33.

[46] A. Krogh, B. Larsson, G. von Heijne, E.L. Sonnhammer, Predicting transmembrane protein topology with a hidden Markov model: application to complete genomes, Journal of molecular biology 305(3) (2001) 567-80.

[47] C. Cassier-Chauvat, F. Chauvat, Responses to oxidative and heavy metal stresses in cyanobacteria: recent advances, Int J Mol Sci 16(1) (2015) 871-886.

[48] M. Rajkumar, N. Ae, M.N.V. Prasad, H. Freitas, Potential of siderophore-producing bacteria for improving heavy metal phytoextraction, Trends Biotechnol 28(3) (2010) 142-149.

[49] K.F. Mo, Z. Dai, D.S. Wunschel, Production and characterization of desmalonichrome relative binding affinity for uranyl ions in relation to other siderophores, J Nat Prod (2016) 1492-9.

[50] V. Rashmi, M. Shylajanaciyar, R. Rajalakshmi, S.F. D'Souza, D. Prabaharan, L. Uma, Siderophore mediated uranium sequestration by marine cyanobacterium Synechococcus elongatus BDU 130911, Bioresour Technol 130 (2013) 204-210.

[51] M. Miethke, C.G. Monteferrante, M.A. Marahiel, J.M. van Dijl, The Bacillus subtilis EfeUOB transporter is essential for high-affinity acquisition of ferrous and ferric iron, Biochim Biophys Acta 1833(10) (2013) 2267-2278. 
[52] M.B. Rajasekaran, S.A. Mitchell, T.M. Gibson, R. Hussain, G. Siligardi, S.C. Andrews, K.A. Watson, Isolation and characterisation of EfeM, a periplasmic component of the putative EfeUOBM iron transporter of Pseudomonas syringae pv. syringae, Biochem Bioph Res Co 398(3) (2010) 366-371. [53] J. Cao, M.R. Woodhall, J. Alvarez, M.L. Cartron, S.C. Andrews, EfeUOB (YcdNOB) is a tripartite, acid-induced and CpxAR-regulated, low-pH Fe2+ transporter that is cryptic in Escherichia coli K-12 but functional in E. coli O157:H7, Mol Microbiol 65(4) (2007) 857-75.

[54] B.D. Stewart, R.T. Amos, S. Fendorf, Effect of uranium(VI) speciation on simultaneous microbial reduction of uranium(VI) and iron(III), J Environ Qual 40(1) (2011) 90-97.

[55] M. Hemadi, N.T. Ha-Duong, J.M. El Hage Chahine, Can uranium be transported by the ironacquisition pathway? Ur uptake by transferrin, J Phys Chem B 115(14) (2011) 4206-4215.

[56] M. Matsubara, T. Mizuno, The SixA phospho-histidine phosphatase modulates the ArcB phosphorelay signal transduction in Escherichia coli, FEBS letters 470(2) (2000) 118-24.

[57] L.E. Macaskie, G. Basnakova, Microbially-enhanced chemisorption of heavy metals: a method for the bioremediation of solutions containing long-lived isotopes of neptunium and plutonium, Environ Sci Technol 32(1) (1998) 184-7.

[58] M.J. Beazley, R.J. Martinez, P.A. Sobecky, S.M. Webb, M. Taillefert, Uranium biomineralization as a result of bacterial phosphatase activity: Insights from bacterial isolates from a contaminated subsurface, Environ Sci Technol 41(16) (2007) 5701-5707.

[59] S. Kulkarni, C.S. Misra, A. Gupta, A. Ballal, S.K. Apte, Interaction of Uranium with Bacterial Cell Surfaces: Inferences from Phosphatase-Mediated Uranium Precipitation, Appl Environ Microbiol 82(16) (2016) 4965-74.

[60] L. Mondani, L. Piette, R. Christen, D. Bachar, C. Berthomieu, V. Chapon, Microbacterium lemovicicum sp. nov., a bacterium isolated from a natural uranium-rich soil, Int J Syst Evol Microbiol 63(Pt 7) (2013) 2600-6. 
Table 1. Functional classification of the proteins detected by at least two peptides.

\begin{tabular}{|l|c|c|}
\hline \multicolumn{1}{|c|}{ COG category } & $\begin{array}{c}\text { Relative } \\
\text { abundance (\%) }\end{array}$ & $\begin{array}{c}\text { Number of } \\
\text { proteins }\end{array}$ \\
\hline Hypothetical protein & 14,6 & 223 \\
\hline Amino acid transport and metabolism & 11,0 & 168 \\
\hline Translation, ribosomal structure and biogenesis & 9,3 & 142 \\
\hline Carbohydrate transport and metabolism & 8,8 & 135 \\
\hline Transcription & 6,2 & 95 \\
\hline Energy production and conversion & 5,5 & 84 \\
\hline Coenzyme transport and metabolism & 5,3 & 82 \\
\hline General function & 5,1 & 78 \\
\hline Lipid transport and metabolism & 4,4 & 67 \\
\hline Nucleotide transport and metabolism & 4,3 & 66 \\
\hline Posttranslational modification, protein turnover, chaperones & 4,0 & 61 \\
\hline Cell wall/membrane/envelope biogenesis & 3,9 & 60 \\
\hline Replication, recombination and repair & 3,9 & 60 \\
\hline Signal transduction mechanisms & 3,6 & 55 \\
\hline Function unknown & 2,8 & 43 \\
\hline Inorganic ion transport and metabolism & 2,8 & 43 \\
\hline Defense mechanism & 1,3 & 20 \\
\hline Cell cycle control, cell division, chromosome partitioning & 1,1 & 17 \\
\hline Secondary metabolites metabolism & 1,0 & 16 \\
\hline Cell motility & 0,5 & 8 \\
\hline Intracellular trafficking, secretion, and vesicular transport & 0,5 & 8 \\
\hline RNA processing and modification & 0,1 & 1 \\
\hline
\end{tabular}




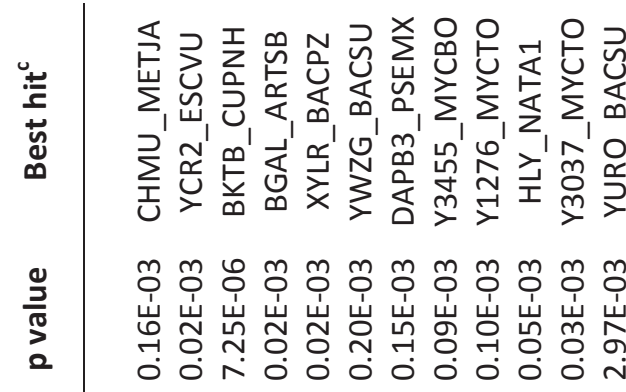

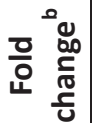

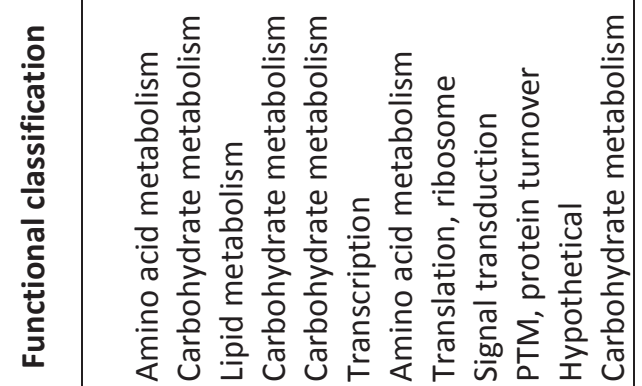

흘

$\frac{5}{3}$

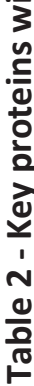

ธั

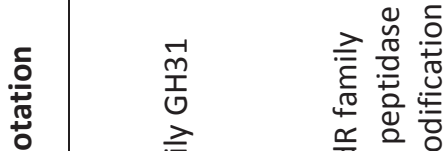

$\frac{\lambda}{\overline{\frac{E}{\sigma}}}$

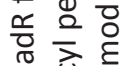

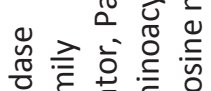

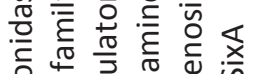

원

$\frac{\pi}{0}$

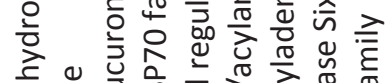

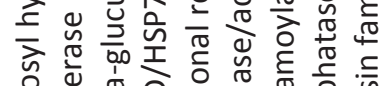

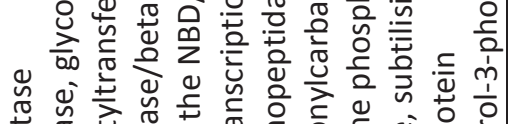

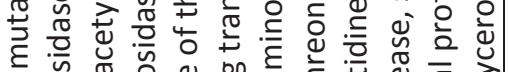

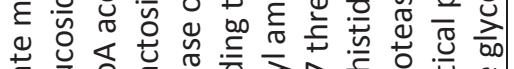

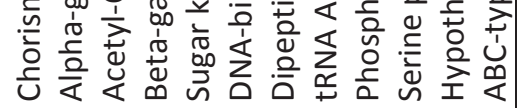

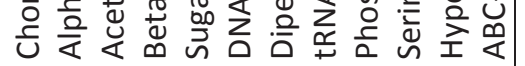

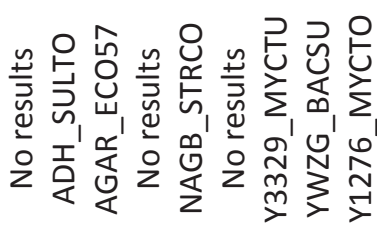

๖ำ

岁嵌㟧㟧山㟧

नㅊํํ पु

mव

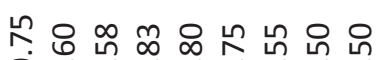

$\dot{-} \dot{\sim} \ddot{m} \ddot{m} \dot{m} \ddot{m} m$

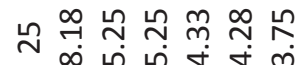

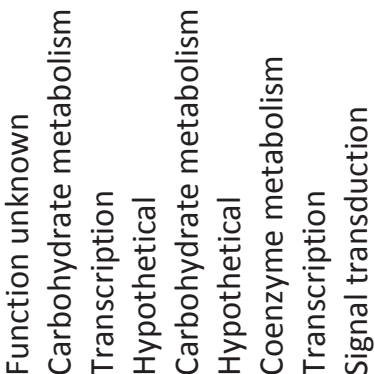

在產

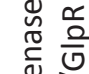

잉 중

늘

है हो

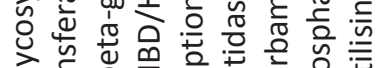

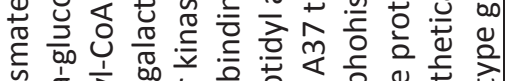

일

T)

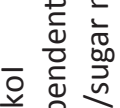

永造产

苛衣盛

흔 楁

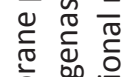

है

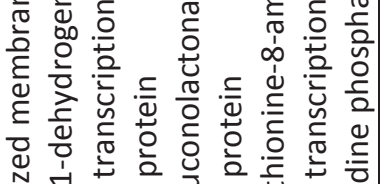

는

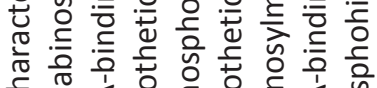

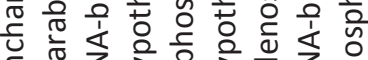

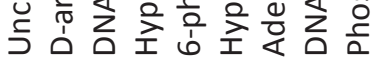

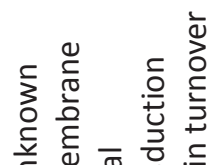

ड

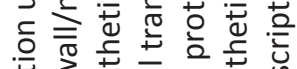

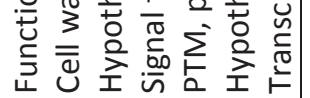

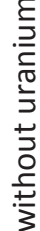

ญ

高

웅

흠

贻

垔

है

齐

每

는

x

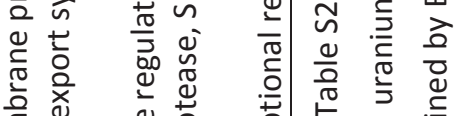

है

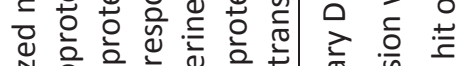

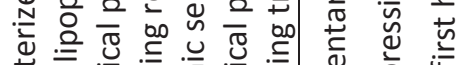

चٓ

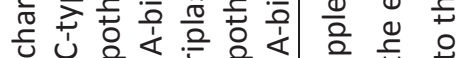

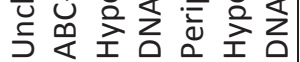

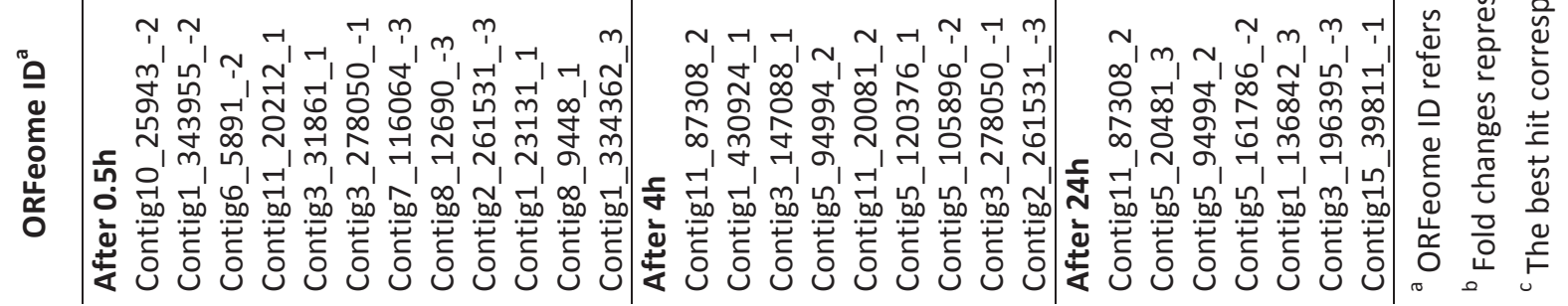


Figure 1 - Shotgun nanoLC-MS/MS strategy used for the proteome analysis of Microbacterium oleivorans A9 under uranium exposure or not. A total of 24 samples were processed: four biological replicates for each time point at $0,5 \mathrm{~h}, 4 \mathrm{~h}$ and $24 \mathrm{~h}$ of exposure. After lysis, the proteins were subjected to a short SDS-PAGE migration before trypsin proteolysis in-gel. A Q-Exactive HF mass spectrometer was used to identify the resulting peptides.

Figure 2 - Venn diagram showing the number of proteins with significant abundance changes in the three sampling time points.

Figure 3 - Example of the phenylalanine, tyrosine and tryptophan biosynthesis pathways. The boxes represent the branched metabolic pathways. The enzymes are identified through their EC number. Proteins detected by proteogenomics are highlighted in red, proteins more abundant upon uranium exposure are indicated in blue and proteins predicted in the genome but not detected by proteomics are in grey. The genes' ID corresponding to the enzymes are as follow: 1.3.1.12:

MicroBact_A9DB\#Contig4_204950_-2, 2.4.2.18: MicroBact_A9DB\#Contig4_125788_-1, 2.5.1.19:

MicroBact_A9DB\#Contig2_13726_-1, 2.5.1.54: MicroBact_A9DB\#Contig4_169845_-3, 2.6.1.1:

MicroBact_A9DB\#Contig12_70604_2, 2.6.1.9: MicroBact_A9DB\#Contig7_122729_2, 2.7.1.71:

MicroBact_A9DB\#Contig1_401394_-3, 4.1.1.48: MicroBact_A9DB\#Contig1_371158_-1, 4.2.1.10:

MicroBact_A9DB\#Contig1_399335_-2, 4.2.1.20: MicroBact_A9DB\#Contig1_369105_-3, 4.2.1.51:

MicroBact_A9DB\#Contig5_42426_3, 4.2.1.91: MicroBact_A9DB\#Contig3_67122_3, 4.2.3.5:

MicroBact_A9DB\#Contig1_401926_-1, 5.4.99.5: MicroBact_A9DB\#Contig10_25943_-2, 6.1.1.1:

MicroBact_A9DB\#Contig7_15747_3, 6.1.1.20: MicroBact_A9DB\#Contig7_133127_2.

Figure 4-Genomic context of the polyphosphate kinase. Fold-change $(\mathrm{FC})$ are indicated for the first time point of sampling (0.5h). Proteins for which the gene name is in bold were detected by proteomics. 
647 List of supplementary material

648 Supplementary Table S1. List of proteins and their spectral count in A9 samples in the first 649 proteogenomic search.

650 Supplementary Table S2. List of proteins and their spectral count in A9 samples in the 651 second round search. NSAF: Normalized Spectral Abundance Factor; SC: Spectral Count 


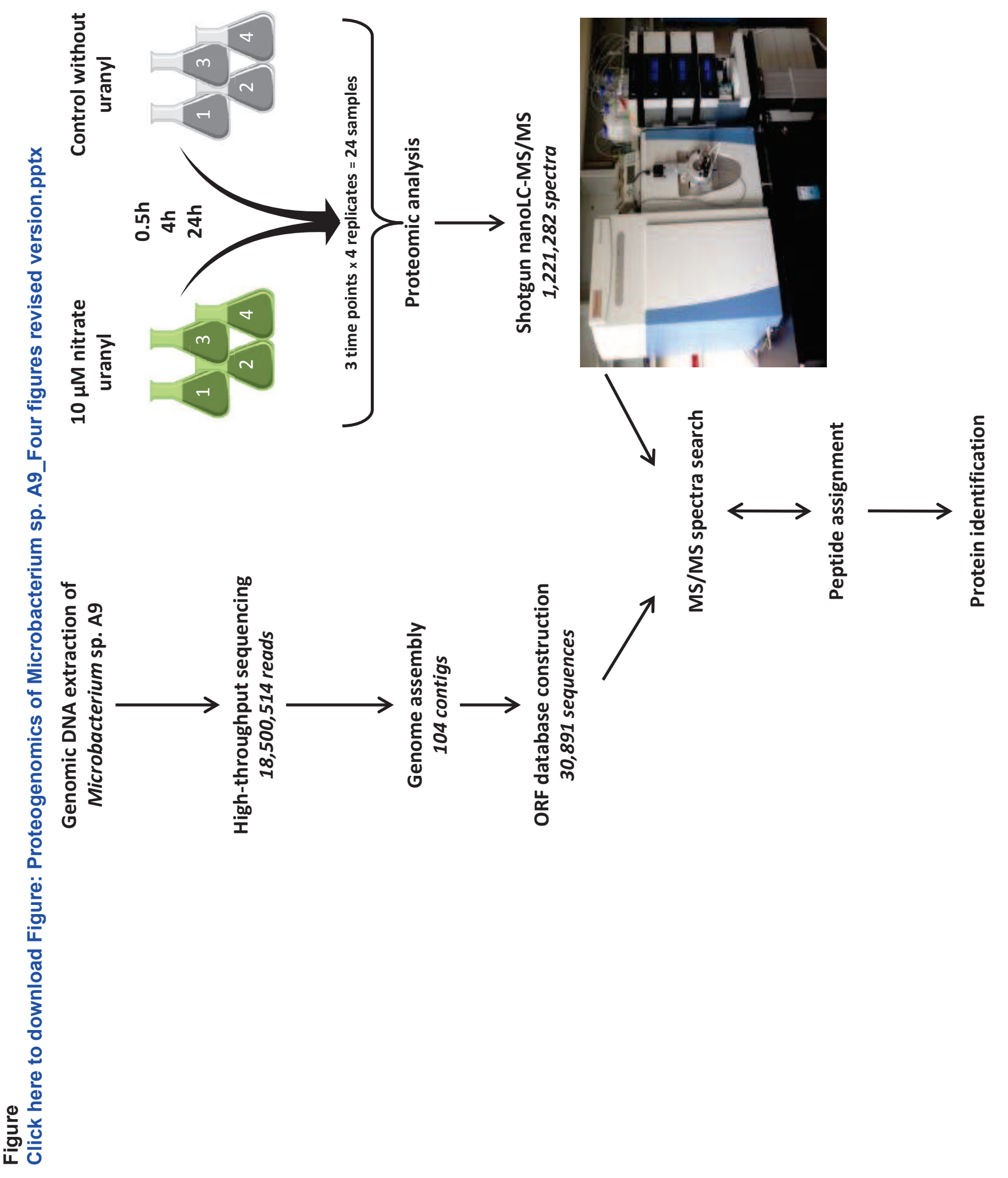




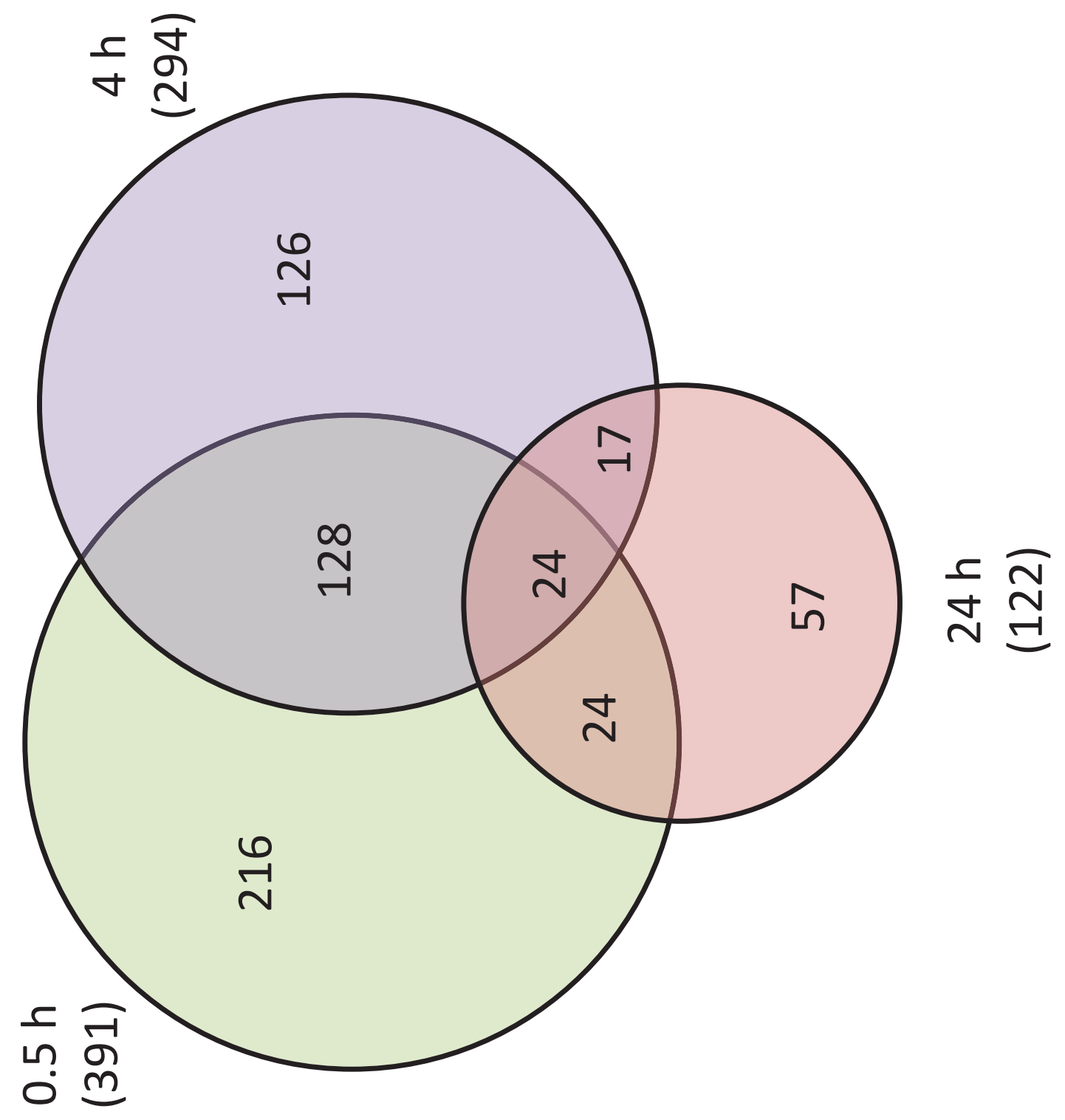




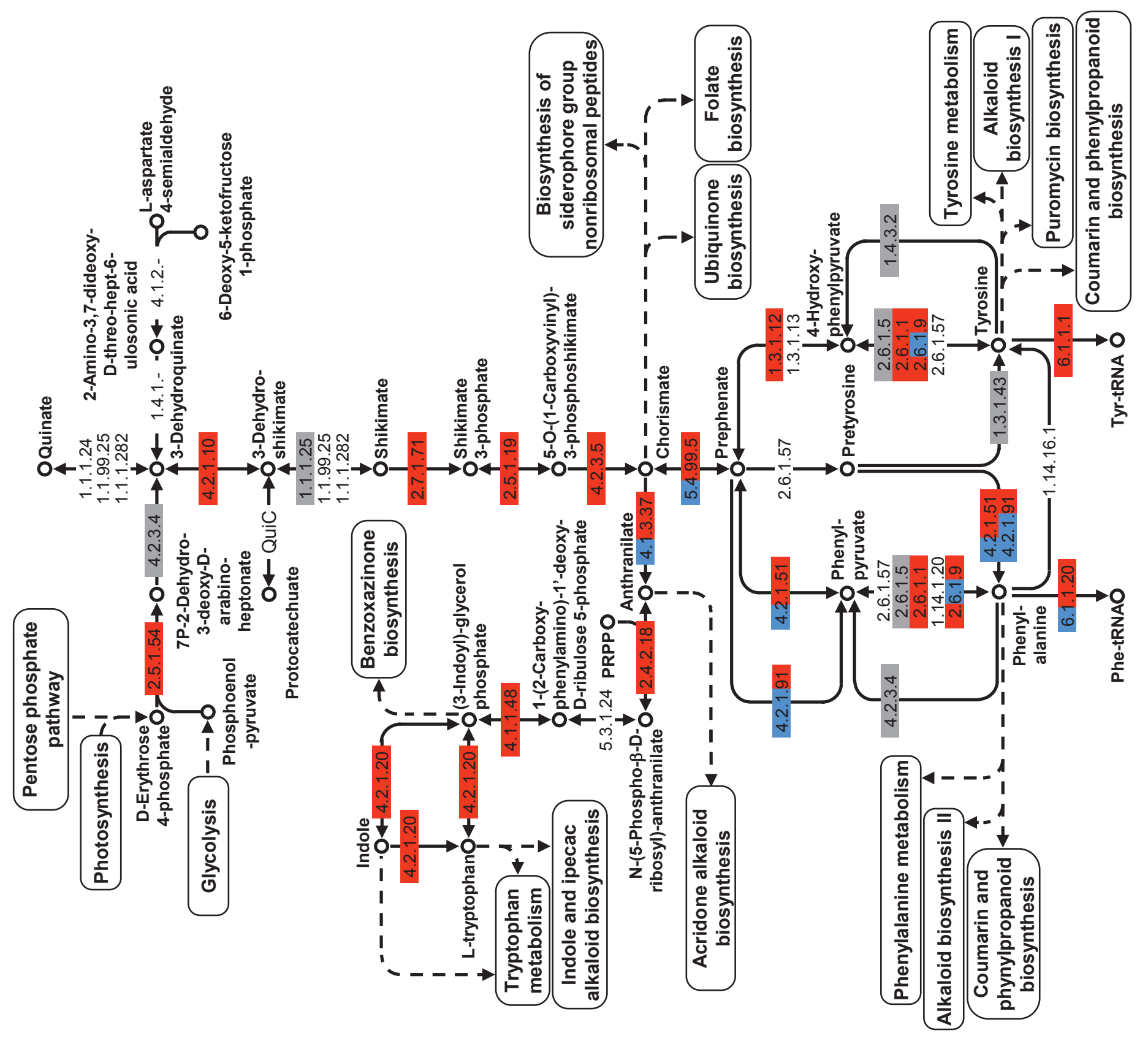




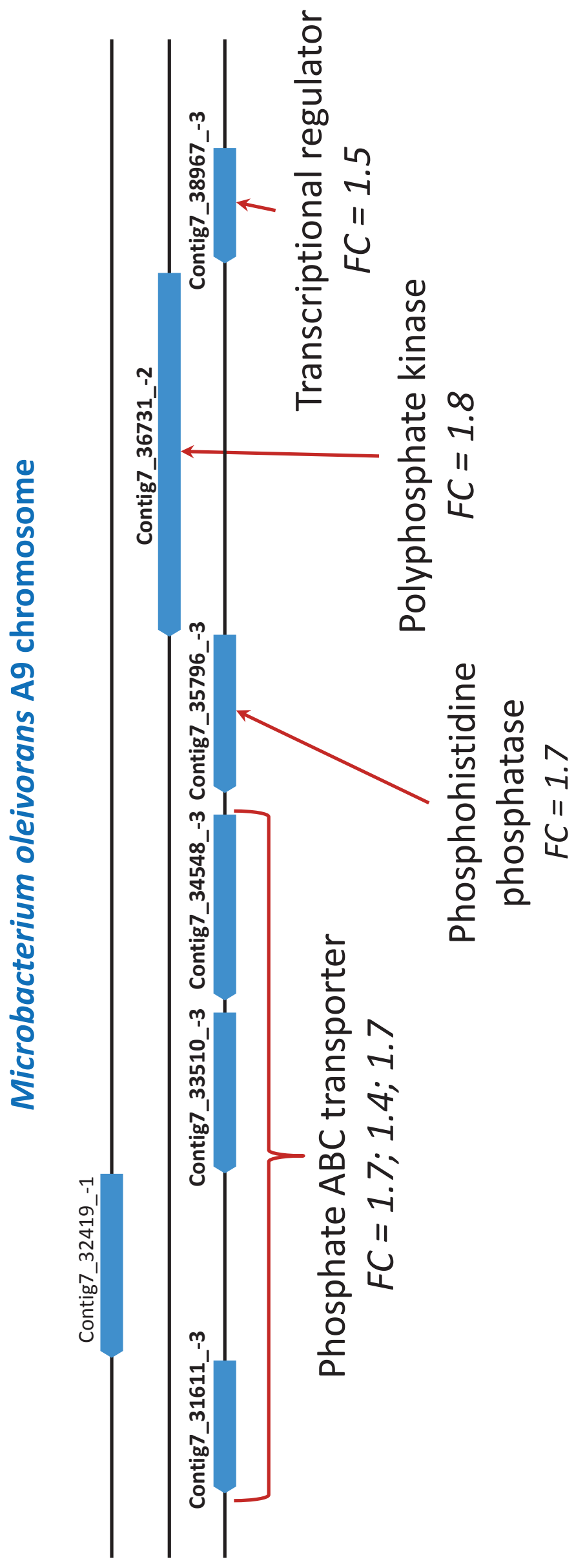

